\title{
Design and Implementation of an Efficient Hybrid System for Electricity Production
}

\author{
Luís P. M.Fernandes ${ }^{*}$, João M. G. Figueiredo ${ }^{* *}$ \\ *IPP-ESTG, Portalegre, CEM Mechatronics Group University of Évora, Portugal, lpedro@estgp.pt \\ ** CEM Mechatronics Group University of Évora, Portugal, IDMEC-IST - Technical University Lisbon, \\ Portugal, jfig@uevora.pt
}

\begin{abstract}
This paper aims to develop a new method for the economical evaluation of Hybrid Systems for electricity production. The different types of renewable sources are specifically evaluated in the economical performance of the overall equipment. The presented methodology was applied to evaluate the design of a photovoltaic-wind-diesel hybrid system to produce electricity for a community in the neighbourhood of Luanda, Angola.
\end{abstract}

\section{Keywords}

Hybrid systems, solar energy, wind energy, rural electrification

\section{Introduction}

The intensive consumption of fossil combustibles is the main cause for the negative impact on our atmosphere. In fact, the fossil combustibles are the main energetic source that sustains the worldwide development. Both major world energetic necessities on thermal and mechanical power are mainly delivered by fossil combustibles.

Today, due to the increasing international concern on the Earth climatic changes we are assisting to an intense research on alternative energetic sources. Among these sources the renewable energies are strongly motivating the research community. This paper focus on two renewable sources: wind power and solar photovoltaic $(\mathrm{PV})$. Both these energetic sources are clean and worldwide available. The comparative advantages of these energetic sources in relation to other renewable energies are demonstrated by the intense expansion of both wind and photovoltaic (PV) production plants, mainly in the industrialized world. This expansion is not due to direct exploration costs but mainly motivated by its reduced impact on environment. However, these renewable resources are extremely useful in lowdeveloped countries, with small needs on electricity and low density populations, where small communities are distributed along great geographical extensions.

The coverage of long distances by electric distribution networks are extremely expensive and completely away from the economical budget of poor countries, especially in Africa. In these cases, of distant rural communities, the electricity generation by means of photovoltaic or wind systems is financially advantageous, relatively to transported electricity through standard networks.
The price competitiveness of diesel generators along with its high robustness and high quality standards has led these generators to the most used solution when remote sites needed to be fed with electric power. However, the continuous rise on fossil combustibles is bringing the renewable energy, mainly wind generators and solar photovoltaic panels, as interesting alternatives to diesel generators. Today we are facing a situation where the costs between several systems: wind, photovoltaic, diesel or even a PV-Wind-Diesel hybrid solution, are very close and the development of a systematic methodology is needed to take a sound decision on the investment.

A correctly designed photovoltaic-wind-diesel hybrid system enlarges considerably both the diesel generator lifecycle as well as the batteries lifecycle, when referring to the widespread off-grid generator systems. Both benefits need to be correctly accounted in the evaluation process, as maintenance costs are reduced significantly in the case of a PV-wind-Diesel solution.

In this context, the design of hybrid systems is a relevant issue. An ideal system has to supply, at any given time of the month, an instantaneous energy $E_{S}$ that equals the consumed energy by all system loads $\mathrm{E}_{\mathrm{L}}$.

$$
\mathrm{E}_{\mathrm{S}}=\mathrm{E}_{\mathrm{L}}
$$

A sub-sized system obviously doesn't satisfy the demand on electric power and, on the other hand, a over-sized system can be completely prohibitive due to economical and financial indicators [1], [2]. This paper aims to develop a new method to evaluate the design of a PV-Wind-Diesel Hybrid System for electricity production. The different types of renewable sources are specifically evaluated in the economical performance of the overall equipment. The presented methodology was applied to evaluate the design of a PV-wind-diesel hybrid system to produce electricity for a community in the neighbourhood of Luanda, Angola.

\section{Methodology Description}

Before we begin the design of a PV-wind-diesel hybrid system we need to know the following main available natural resources: wind profile and solar radiation. In case we have suitable amplitudes of both renewable energetic sources we can actually initiate the design of the hybrid system. First of all we need to calculate the dimension of the following elements: PV-system, wind-generator, diesel 
generator, CC-CA converter and battery set. Following the work from Celik [2], we propose the following methodology:

1) Calculate the PV-area and the wind-area needed for each month, covering the monthly demand on electric power. Then proceed with the calculation of the equipment size, taking into account the 12months average - $A_{P V}$ and $A_{W}-$ (eqs. 2, 3) and the correspondent standard deviations $\left(\sigma_{P V}\right.$ e $\left.\sigma_{W}\right)$. This statistical analysis is based on the probability density associated with each natural resource.

$$
\begin{gathered}
A_{F V}=\frac{E_{S}}{e_{F V}} \\
\mathrm{~A}_{\mathrm{FV}}=\frac{\mathrm{E}_{\mathrm{S}}}{\mathrm{e}_{\mathrm{A}}}
\end{gathered}
$$

where:

$E_{S}$ : Total energy supplied by the Hybrid System [kWh]

$$
\begin{aligned}
& \mathrm{e}_{\mathrm{PV}} \text { : specific PV-energy }\left[\mathrm{kWh} / \mathrm{m}^{2}\right] \\
& \mathrm{e}_{\mathrm{W}} \text { : specific wind-energy }\left[\mathrm{kWh} / \mathrm{m}^{2}\right]
\end{aligned}
$$

2) Resize the calculated dimension $A_{P V}$ and $A_{W}$ using a factor dependent on $\sigma_{P V}$ and $\sigma_{W}$, respectively.

3) Calculate the number of standard PV-models and wind-generators according to the market availability, dividing the total power calculated by the standard power unit available in the market.

4) Calculate the life-cycle costs associated with different percentages of PV-wind composition, and optimize this cost function. The optimal Hybrid system design corresponds to the minimization of the cost function (fig. 1).

Referring now to the evaluation of the output power that the hybrid system should deliver, this methodology accounts for the following factors:

1) all known electric power needs (loads) have to be considered;

2) power losses in the distribution network and in the inverter system are considered;

3) the technical data supplied by PV-producers and wind-generator producers as well as the site measurements of wind profile and solar radiation are the basis for the $\mathrm{PV}$ and wind specific energy determination;

4) The maximum of the power load curve, added to the calculated losses in the system, determines the size of: the generator group, the power module, and the converter DC-AC.

5) Finally the battery set is designed according to the autonomy required to the projected Hybrid system. The integration of the power load curve for the projected autonomy time-period gives the net output supply for the battery set.
The determination of the optimal composition PV-Wind Hybrid system is made through the fraction variation PVWind, regarding the Project associated costs with each configuration [4], [5]. The optimal PV-Wind configuration, for a specific site, corresponds to the minimum Project cost as illustrated in figure 1.

This methodology was applied to design a photovoltaicwind-diesel hybrid system to produce electricity for a community in the neighbourhood of Luanda, Angola.

The resulted net energy costs were very satisfactory regarding the economical possibilities of these African communities.

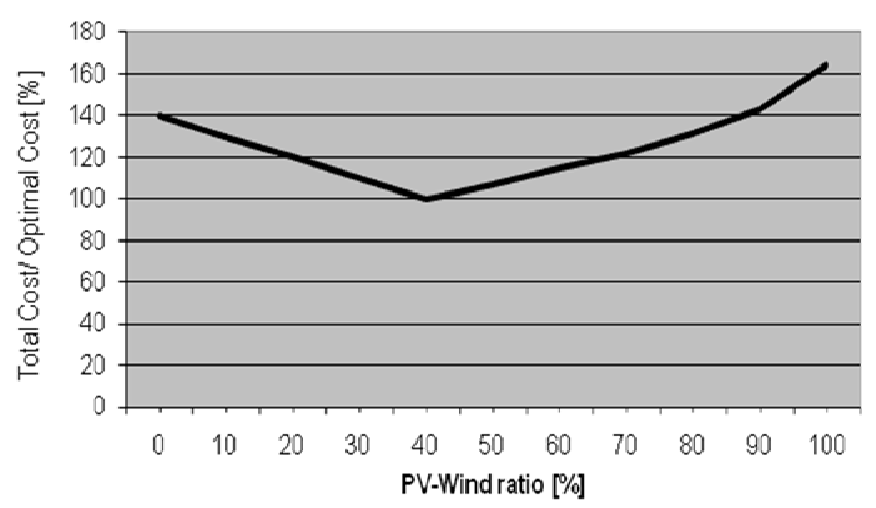

Fig. 1. Costs associated with different PV-Wind combinations

\section{Case study}

\section{A. Description}

This study was made in a community near by Luanda, in Angola. This community like many others in Angola doesn't have any energy supply provided by a dealership, thus have to use individual generators, mostly diesel ones. It was made a survey to identify the installed loads, likewise a calculation of the load to be installed, as this study of electric energy supply through a mini-net, will have as its purpose to supply electric energy to a duelling set which doesn't have its own energy production and will be connected to this mini-net. It was also made a local natural resources survey to analyse potential energetic gains. It was proved a good solar potential and a good wind potential due to the fact that this community is located in a coastal site.

\section{B. Evaluation of Energy Demand}

Once some of the dwellings of this small community already have its own electric energy production through generators, in the energetic needs survey, this production was counted. The features of the individual electric energy production supplied by existing generators in this community are shown on table 1 . On this table we can see that 10 generators are working, mainly diesel supplied. Table 1 contents were collected through individual interviews to the local owners. 


\begin{tabular}{|c|c|c|}
\hline Home n. & $\begin{array}{c}\text { Installed } \\
\text { Power }(\mathrm{kW})\end{array}$ & $\begin{array}{c}\text { Mean } \\
\text { Consumption/month } \\
(\mathrm{kWh} / \text { month) }\end{array}$ \\
\hline 1 & 0,7 & 70 \\
\hline 2 & 0,8 & 95 \\
\hline 3 & 0,9 & 160 \\
\hline 4 & 1,5 & 145 \\
\hline 5 & 1,5 & 150 \\
\hline 6 & 3,0 & 350 \\
\hline 7 & 2,0 & 200 \\
\hline 8 & 0,9 & 140 \\
\hline 9 & 0,8 & 50 \\
\hline 10 & 1,4 & 90 \\
\hline Total & 13,5 & 1450 \\
\hline
\end{tabular}

\section{Evaluation of Energetic Sources}

\section{Photovoltaic Energy}

The survey on the solar potential of the community was made through the data acquisition by a solar-meter station installed on the site. The data were obtained in an hourly basis. Figure 3 shows the monthly average daily radiation, in the year 2007 , on a plane at an angle of $30^{\circ}$ in relation to the horizontal position, towards south.

The average daily radiation in the year 2007 was 4,75 $\mathrm{kWh} / \mathrm{m}^{2}$.

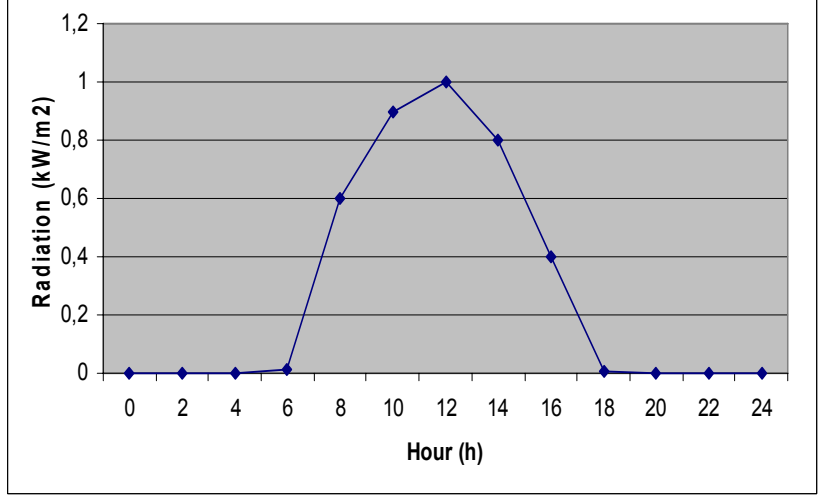

Fig.3 - Monthly average of daily radiation

Finally, to design the PV-unit we have to consider additionally, that the PV-cell performance depends on the solar radiation, on the temperature, on the tension and on the dirt located on the panel surface.

\section{Wind Energy}

In figure 2, it is shown the daily electric energy consumption. The data was collected through individual interviews to local owners. This community shows typical features of rural environments relatively to the use and consumption of electric energy.

Based on the local owner interviews it was estimated a monthly consumption of $145 \mathrm{kWh} /$ month, for each one of the future 15 dwellings, that will be connected to the mini-network. This estimate leads to a daily consumption of $2,9 \mathrm{kWh} / \mathrm{day}$, with a small consumption over day, between $6 \mathrm{AM}$ and $5 \mathrm{PM}$ and with a night spike between $5 \mathrm{PM}$ and $0 \mathrm{AM}$.

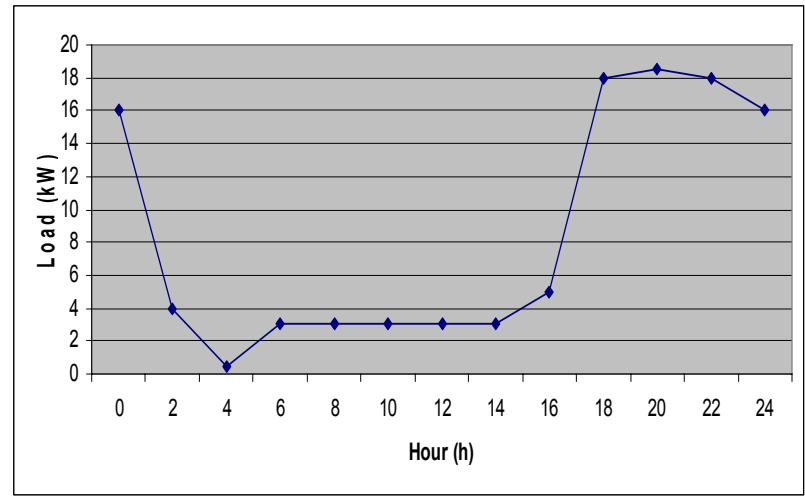

Fig. 2 - Daily electric energy consumption

The wind resources' survey was based mainly on experimental data acquired through a $30 \mathrm{~m}$-tower equipped with an anemometer. Figure 4 shows the monthly average wind speed at a height of $30 \mathrm{~m}$, in the year 2007 .

The average wind speed registered shows a value of 4,1 $\mathrm{m} / \mathrm{s}$, for the year 2007. Another important data to evaluate the wind potential is the rate of the registered wind speed's occurrences. Figure 5 shows the histogram registered in 2007 , correspondent to a $30 \mathrm{~m}$ height.

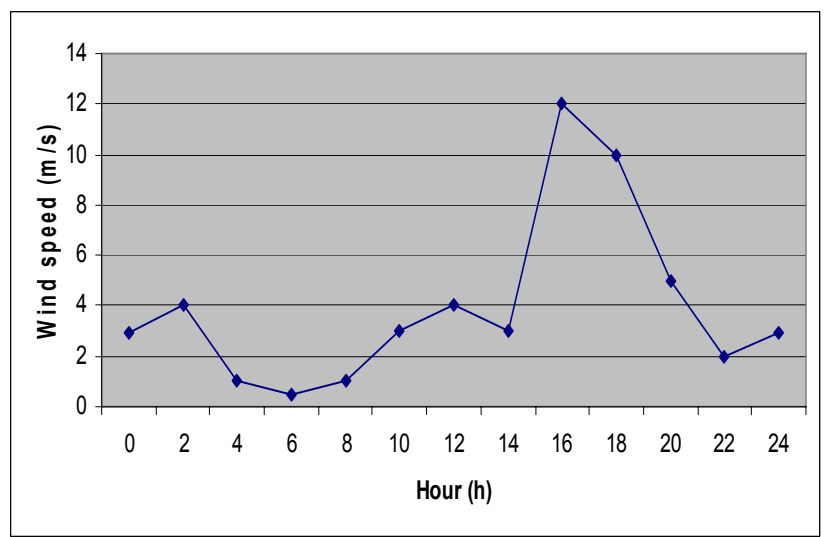

Fig.4. Monthly average of Wind speed 


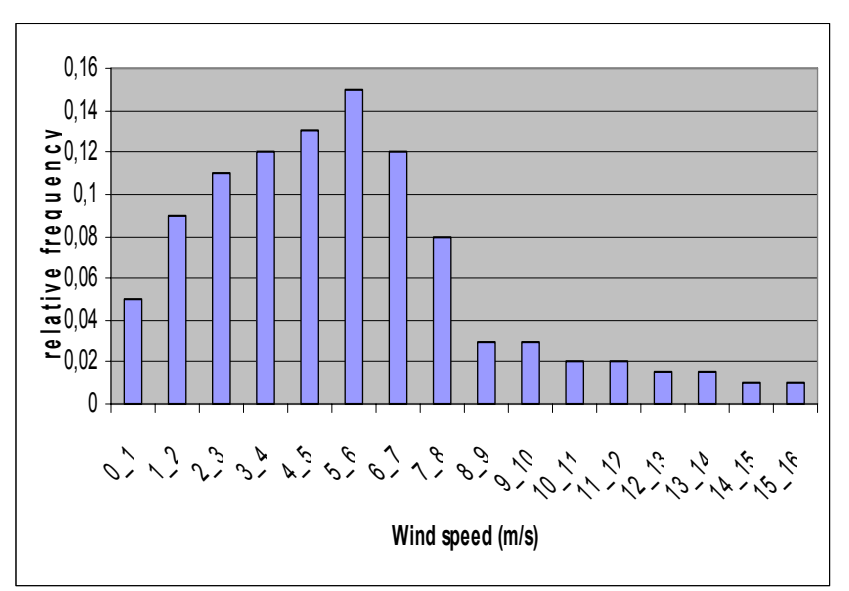

Fig. 5 Wind histogram - 2007

With the final purpose of getting an estimated wind potential at different heights it was calculated the local roughness factor. Evaluating the terrain and the preponderance of the wind's incidence, it was possible to determinate the local roughness using equation 4.

$$
\mathrm{v}(\mathrm{z})=\mathrm{v}_{\mathrm{r}}\left(\frac{\mathrm{z}}{\mathrm{z}_{\mathrm{r}}}\right)^{\alpha}
$$

Where $\mathrm{v}(\mathrm{z})$ is the speed at a $\mathrm{z}$ height, $\mathrm{v}_{\mathrm{r}}$ is the speed at a reference height $z_{r}$ and the parameter $\alpha$ is dependent on the local terrain roughness.

After the site evaluation had been made, the terrain features were observed. These main features are: mountainous, open sea and medium size vegetation. The distance between the tower and the open sea is about 500 meters. Additionally on this part of the site there is some small vegetation and small sand-hills. Figure 6 characterizes the wind geographical distribution with the rates correspondent to $30 \mathrm{~m}$ height.

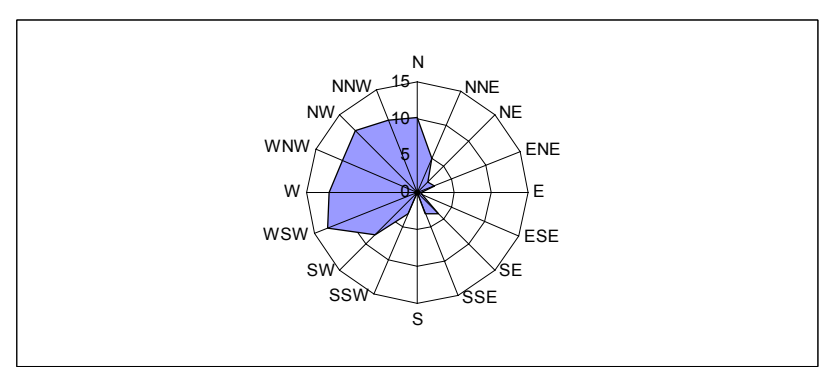

Fig. 6. Rates of wind occurrence

The calculated roughness factor is 0,35 for the predominant wind region.

A survey on the performance of typical available small sized turbines, at a 50m-height, is illustrated on table 2 . This data shows a significant improvement on the equipment efficiency when we increase the height from $30 \mathrm{~m}$ to $50 \mathrm{~m}$. This reason explains why we verify that the usual wind-turbines are found to be installed at a $50 \mathrm{~m}$ height.

At a 50m height the ratio EAWE/IWE (EAWE = Expected Available Wind Energy; IWE = Installed Wind Energy) has a typical improvement of ca. $20 \%$ [6].

\begin{tabular}{|c|c|c|c|}
\hline Wind Generator & $\begin{array}{c}\text { Power } \\
(\mathrm{kW})\end{array}$ & $\begin{array}{c}\text { EAWE/ } \\
\text { IWE } \\
(30 \mathrm{~m})\end{array}$ & $\begin{array}{c}\text { EAWE/ } \\
\text { IWE } \\
(50 \mathrm{~m})\end{array}$ \\
\hline Westwind & 5 & 15 & 20 \\
\hline Westwind & 10 & 12 & 18 \\
\hline Westwind & 20 & 13 & 22 \\
\hline
\end{tabular}

Table 2 - EAWE/IWE [6]

\section{System Design}

Besides the components dimensioning, based on data evaluation, it's also important to take into account some features of the local resources available in the site. Figure 7 and figure 8 represent the assumed annual power profile for both PV and wind resources. A quick analysis of these data permits to observe that there isn't any seasonal complementarity between the solar and the wind resources. However, there is a daily complementarity between solar and wind resources as it is shown in figs. 7 and 8 . This fact contributes to a better utilization of the available resources.

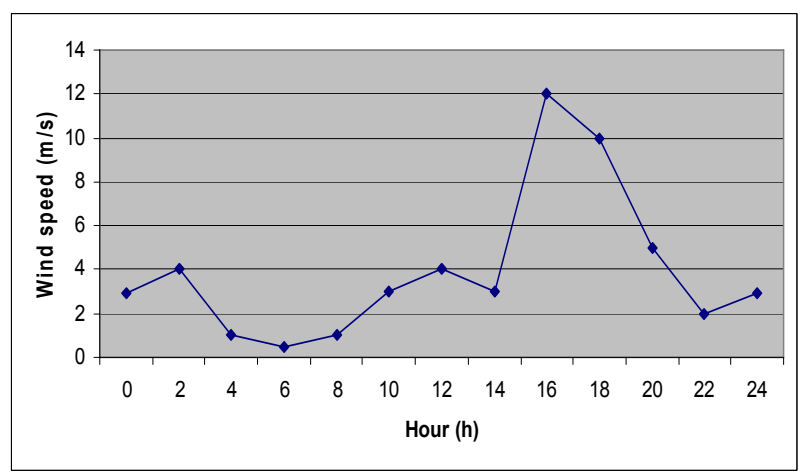

Fig.7. Annual power profile: wind resources (assumed profile)

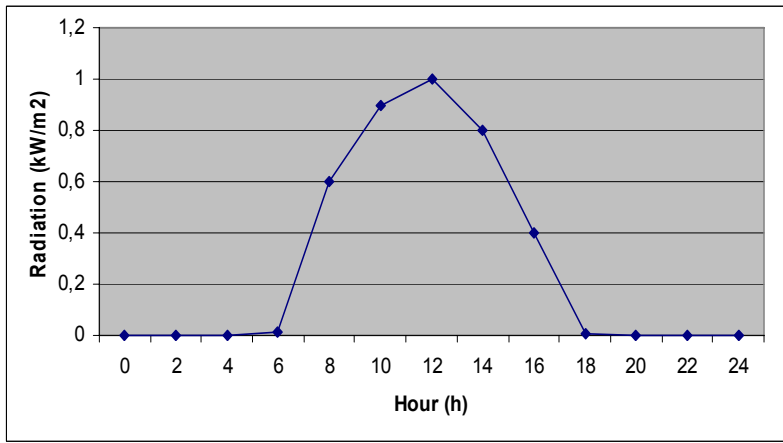

Fig. 8. Annual power profile: PV resources (assumed profile)

Having now the data that characterizes both the energy demand (loads) and the available renewable resources (data for PV and Wind) the hybrid system can now be completely designed.

For the PV-generator it was chosen the 85hp BP Solar panel [7]. In relation to the wind-generator, the $10 \mathrm{~kW}$ Westwind turbine was selected [6].

Both equipments have shown the best technical features in relation to the studied local available resources.

Finally it was assumed a 5\% losses in the chain distribution and a $90 \%$ conversion efficiency for the overall equipment. 
Table 3 shows the necessary power surfaces for both PV and Wind generators independently, in order to supply the community monthly load.

\begin{tabular}{|c|c|c|c|}
\hline Month & $\begin{array}{c}e P V \\
\left(\mathrm{kWh} / \mathrm{m}^{2}\right)\end{array}$ & $\begin{array}{c}e W \\
\left(\mathrm{kWh} / \mathrm{m}^{2}\right)\end{array}$ & $\begin{array}{c}E_{L} \\
(\mathrm{kWh})\end{array}$ \\
\hline Jan & 20,4 & 33,5 & 3447,3 \\
\hline Fev & 21,2 & 25,3 & 3456,5 \\
\hline Mar & 24,4 & 27,6 & 3233,2 \\
\hline Apr & 19,6 & 22,2 & 3456,5 \\
\hline Mai & 16,4 & 25,3 & 3456,5 \\
\hline Jun & 17,2 & 21,2 & 3456,5 \\
\hline Jul & 16,8 & 22,2 & 3447,4 \\
\hline Aug & 15,6 & 14,6 & 3456,5 \\
\hline Set & 16,4 & 14,6 & 3412,6 \\
\hline Out & 18,8 & 25,3 & 3448,3 \\
\hline Nov & 20,8 & 28,8 & 3456,5 \\
\hline Dez & 20,8 & 33,5 & 3420,2 \\
\hline
\end{tabular}

\begin{tabular}{|c|c|c|}
\hline Month & $\begin{array}{c}A P V \\
\left(\mathrm{~m}^{2}\right)\end{array}$ & $\begin{array}{c}A W \\
\left(\mathrm{~m}^{2}\right)\end{array}$ \\
\hline Jan & 169,0 & 102,9 \\
\hline Fev & 163,0 & 136,8 \\
\hline Mar & 132,5 & 117 \\
\hline Apr & 176,3 & 156 \\
\hline Mai & 210,8 & 136,8 \\
\hline Jun & 201,0 & 157,6 \\
\hline Jul & 205,2 & 155,6 \\
\hline Agu & 221,6 & 236 \\
\hline Set & 208,1 & 233 \\
\hline Out & 183,4 & 136,4 \\
\hline Nov & 166,2 & 120,2 \\
\hline Dec & 164,4 & 102 \\
\hline
\end{tabular}

Table 3 - Min. surfaces needed for PV and Wind generators, working independently

The PV-generator and the Wind-generator average areas are $183,5 \mathrm{~m}^{2}$ and $149,2 \mathrm{~m}^{2}$. The standard-deviations are $26,2 \mathrm{~m}^{2}$ and $44,1 \mathrm{~m}^{2}$ respectively. Adding the standarddeviation value to the correspondent average area we got the total area that best ensures the technical-economical relation, as it was described in section 2. These values for $\mathrm{PV}$ and Wind areas are independent quantities that can supply independently the total demanded energy. Finally the total area values are $209,7 \mathrm{~m}^{2}$ and $193,3 \mathrm{~m}^{2}$ for the $\mathrm{PV}$-generator and for the Wind-generator respectively. Dividing these total values by the unitary performance values associated with the selected PV-panels and Windgenerators we get the max. number of PV-panels and Wind-generators.

For our case study, this methodology leads us to $233 \mathrm{PV}-$ modules and 7 Wind generators.

Now to determine the optimal combination PV-Wind generators, for the designed hybrid system, we lead an economical analysis.

The Net Present Value (NPV) methodology was used to perform the economical evaluation of the different analysed PV-Wind configurations.

Each studied PV-Wind configuration was evaluated over a life period of 20 years. The considered capital cost was 7\% per year.

Figure 9 summarizes the results obtained in the developed NPV analysis. It is observed that the optimal operating point is obtained for a combination of ca. $40 \%$ Windgenerators ( 3 Wind turbines) and $60 \%$ of PV-generators (140 PV-panels).

Finally in order to assure 1-day energy autonomy, a battery set of $80 \mathrm{kWh}$, adjusted for a $50 \%$ maximum discharge depth, was considered.

The inverter and the generator group were designed to comply the maximal load which was under $20 \mathrm{~kW}$, according fig. 2 .

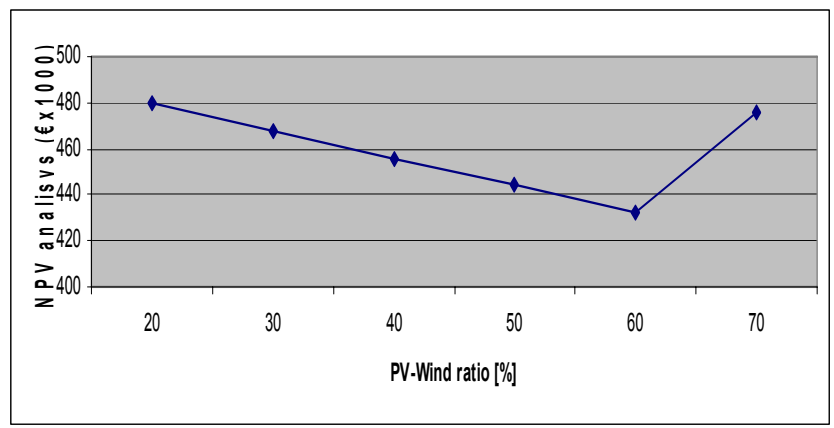

Fig. 9 - NPV analysis

\section{Conclusions}

This methodology had shown to be, both technical and economically, more advantageous than other project methods based on the data regarding the "worst month" scenario [3]. Since the "worst month" scenario methodology ignores the performance-cost relationship and it concentrates on the system performance alone, the obtained results can be misleading. The developed methodology has the advantage that it integrates all economical and financial factors, present in the project of electric energy delivery systems.

\section{Acknowledgment}

This work was partially funded by the FCT through program POCTISFA-10-46-IDMEC, subsidized by FEDER and by the Project PETER PIC Interreg IIIA SP6.E53/03.

\section{References}

[1] J. Gordon (Editor), "Solar Energy - The State of the Art", ISES Position Papers, James \& James, 2001.

[2] Celik AN.; "Techo-economic analysis of autonomous pv-wind hybrid energy systems using different sizing methods"; Energy Conversion and Management, Vol. 44, 2003, Pages 1951-1968.

[3] Protogeropoulos C, BriKworth BJ, MArshalll R.; "Sizing and techno-economical optimization for hybrid solar pv-wind power systems with battery storage“. Int JEnergy Res 1997; 21:1-15.

[4] Solarbuzz, "Solar Electricity Prices", (http://www.solarbuzz.com/SolarPrices.html.

[5] AWEA Wind Energy Fact Sheets, "The Economics of Wind Energy", (http://www.awea.org/pubs/factsheets.html)

[6] http://www.westwind.com

[7] http://www.bp.com 